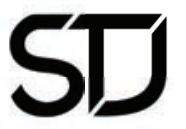

\title{
Geloof sonder sekerhede: Perspektiewe op die gesprek met Ernst Conradie
}

\author{
Van Niekerk, Anton A \\ Universiteit Stellenbosch \\ aavn@sun.ac.za
}

\begin{abstract}
This article continues the discussion with Ernst Conradie in view of his earlier and critical review of the revised edition of Anton van Niekerk's book Geloof sonder sekerhede [Faith without certainties]. The author provides further clarity on his notion of the nature of religious faith which, for him, essentially coincides with the life of love proclaimed and demonstrated by Jesus of Nazareth. The rest of the article contains Van Niekerk's analyses of the three "creative tensions" that Conradie identified in his original discussion of the book. These are the alleged tensions between orthodoxy and orthopraxis, between faith and certainty, as well as between scientific knowledge and the knowledge of faith. Most attention is paid to the last tension which, according to Van Niekerk, reveals an unfounded metaphysical presupposition in Conradie's position, as well as the yielding of too much intellectual territory to scientism in Conradie's insistence on the ontological continuity between God and creation.
\end{abstract}

Key words

Faith; certainty; Conradie; Van Niekerk

\section{Inleiding: Waaroor gaan dit in Geloof sonder Sekerhede?}

Ernst Conradie ontwikkel interessante perspektiewe (Conradie 2015) op die tweede, omvattend hersiene uitgawe van my boek Geloof sonder Sekerhede: Hoe kan ek nog glo? (Van Niekerk 2014; voortaan afgekort tot GSS). Ek beskou sy noukeurige aandag aan en moeite met albei uitgawes van hierdie teks as 'n besondere kompliment deur 'n teoloog wat ek baie hoog ag. Ek verwelkom daarom die geleentheid tot voortgaande gesprek. Conradie se bespreking van GSS plaas 'n hele aantal kwessies op die tafel 
wat behoorlik verreken behoort te word in enige besinning oor 'n meer eietydse geloofsbeskouing, soos GSS bedoel is om te wees.

Ek en Conradie stem myns insiens oor meer dinge met mekaar saam as waaroor ons verskil. Oor enkele kwessies bly daar egter verskille oor wat waarskynlik nie maklik oorbrug kan of sal word nie, en wat hopelik in die toekoms verder ontwikkel sal word as deel van die "kreatiewe spanninge" in hierdie gesprek - en dan wel nie noodwendig die "kreatiewe spanninge" in die teks waarop Conradie wys nie (Conradie 2015:346-348), maar wel die kreatiewe spanninge in die wyer diskoers waarin ek, hy en 'n skare ander skrywers meer duidelikheid probeer vind oor die betekenis van eietydse geloof in 'n toenemend gesekulariseerde wêreld.

Ek gaan hierdie artikel grootliks struktureer op voetspoor van die volgorde van sake wat Conradie in sy bespreking self volg. Ek wil graag begin deur opnuut te beklemtoon wat my breë doelstelling in die boek is, en wat Conradie self in sy eerste paragraaf aansny. Hy skryf "Die argument van die tweede ... uitgawe van 2014 bly dieselfde, naamlik dat die Christelike geloof (al gaan dit dan met onsekerhede gepaard) implikasies het vir die manier waarop ons lewe, veral in die Suid-Afrikaanse konteks." Ek sou hierdie stelling verder wou voer en meer radikaal wou formuleer - nie slegs met verwysing na hierdie tweede uitgawe nie, maar beslis ook met verwysing na wat gebeur in die eerste uitgawe. GSS is nie slegs 'n boek wat besin oor die "implikasies van geloof vir die manier waarop ons lewe" nie. Dit gaan heelwat verder. Dit is 'n teks wat inderwaarheid 'n gans ander geloofsbeskouing as die tradisioneel-gereformeerde beskouing probeer ontwikkel, 'n opvatting van geloof wat die onderskeid tussen geloof en lewe sover moontlik probeer deursny. In die geloofsbeskouing van GSS is geloof na sy wese niks anders nie as 'n manier van lewe.

'n Ander manier om, wat my betref, dieselfde punt te maak, is om te sê dat GSS 'n geloofsbeskouing ontwikkel wat die volle implikasies van die aanspraak dat ons slegs oor God kan praat op grond van Sy Selfopenbaring in die mens Jesus van Nasaret, konsekwent probeer deurtrek. Oor God is daar weinig, indien enigiets, te sê anders as dat dit die poging behels om die lewe van die geloof - daardie lewe wat ons by Jesus sien en leer - te probeer lewe nie. Geloof is doodeenvoudig om die lewe van die Man van Nasaret in elke aspek van 'n mens se eie lewe te probeer naleef. Wat ons omtrent God 
weet en kan sê, word volledig saamgevat in die lewenswyse - die lewe van die liefde - wat ons by Jesus leer. Geloof is niks anders en niks meer as 'n lewenswyse nie. Ek kan uiteraard nie oordeel in watter mate hoofstuk 5 (pp. 115-132) van GSS daarin slaag om hierdie opvatting genoegsaam duidelik te maak nie. Wat ek egter wel (hopelik ondubbelsinnig) kan aanvoer, is dat dit my bedoeling met die boek in die algemeen, en daardie hoofstuk in die besonder, was/is.

'n Mindere punt het betrekking op Conradie se vraag watter denke 'n invloed uitgeoefen het op die etiek van verantwoordelikheid wat ek in hoofstukke 8 en 9 ontwikkel. Die antwoord op daardie vraag is denkers soos Emmanuel Levinas (1985), Hans Jonas (1984) en Zygmunt Bauman (1993), eerder as teoloë soos Bavinck, Noordmans, Van Ruler, Moltmann en Heyns, oor wie Conradie spekuleer as moontlike invloede op my. ${ }^{1}$

Conradie struktureer sy bespreking vervolgens rondom wat hy drie "kreatiewe spanninge" noem wat in die teks van GSS uitkristalliseer. Dit is die vermeende spanninge tussen "ortodoksie en ortopraksie, tussen sekerheid en onsekerheid en tussen geloofskennis en wetenskaplike kennis" (Conradie 2015:346). Conradie ontleen die idee van 'n "kreatiewe spanning" skynbaar aan David Bosch (1991:381-389). ${ }^{2}$ Conradie verduidelik soos volg: "'n Kreatiewe spanning bestaan daar waar daar wel twee kante van 'n saak bestaan wat algemeen erken word. Dit kan daarom nie sonder meer opgelos word deur'n kritiek teen bipolêre denke nie, alhoewel die spanning wel dialekties (en dan altyd voorlopig) opgehef kan word. Dit gaan (...) hier (...) om die spanning vol te hou ter wille van die vrugbaarheid daarvan" (Conradie 2015:346).

Sy verduideliking van hierdie idee word dan gevolg deur 'n taamlik uitvoerige (en onverwagte) bespreking en vergelyking van die verskillende

1 Die boek van Etienne de Villiers (2018) oor die verantwoordelikheidsetiek van Max Weber het pas onder my aandag gekom. Hoewel ek vertroud is met Weber se opstel Politics as vocation en elders daarmee gehandel het (Van Niekerk 2012), is dit bepaald jammer dat ek nie De Villiers se duidelik magistrale boek onder oë kon kry met die hersiening van GSS nie.

2 Hennie Rossouw gebruik in 'n vergelykbare sin die begrip "spanningsvelde" in sy analise van die idee van die universiteit. In laasgenoemde geval is dit dan spanningsvelde tussen identiteit en relevansie, universaliteit en partikulariteit, elitisme en egalitarisme en outonomie en beperking. Sien Rossouw 1993:32-53. 
"kontekste" waarin ek en hy onderskeidelik ons werk doen: in my geval, die Universiteit Stellenbosch, teologies na bewering steeds oorwoeker deur die NG Kerk, en in sy geval, die Universiteit van Wes-Kaapland, waar dinge veel meer ekumenies gesteld is. ${ }^{3}$ My konteks sou dan een wees waarin my lesers primêr NG lidmate is en waar die "hegemonie van Afrikaner nasionalisme en elitisme steeds deurbreek moet word" "4, terwyl sy konteks een is "soos UWK waar 'n 'plek van kwaliteit en 'n plek om in te groei' gevestig moet word" (Conradie 2015:347). Ek het hierdie bespreking vreemd en onvrugbaar gevind. Ek onthou weinig daarvan dat ek die boek spesifiek met die oog op NG lidmate en Stellenbosch se betreurenswaardige politieke geskiedenis in gedagte geskryf het. Die meeste reaksie op die boek het daarby gekom uit die geledere van mense wat die NG Kerk lankal reeds vaarwel toegeroep het.

Hoe ook al, ek meen dat hierdie soort "konteks-analise" van 'n boek liewer gelaat behoort te word, veral as met "konteks" bedoel word die waarskynlike lesers van die boek en die historiese omstandighede waarbinne die skryf van die boek geskied het. Daarmee word uiteraard nie die hermeneutiese beginsel ontken dat die dele van die boek se teks in die lig van die geheel van die boek - ook die "konteks" - gelees moet word nie. Conradie se soort konteksanalise loop egter die gevaar om die betekenis van die teks te veel te laat bepaal deur omskrywinge van die boek se "konteks" eerder as deur wat daadwerklik in die teks staan. Dit behels daarom die gevaar om 'n mens op afdwaalpaaie te lei wat nie vrugbaar is vir die bearbeiding van die intellektuele problematiek van die boek nie. Ek laat hierdie onderwerp dus vir eers daar.

3 Ek dra nie genoeg kennis van UWK se teologiese oriëntasie om my oor hierdie aanspraak uit te laat nie. Wat Stellenbosch betref - en sonder om ongeregtighede van die verlede te probeer verskoon - weet ek wel dat die Fakulteit Teologie 'n veel meer ekumeniese samestelling en aanslag het as ooit in die verlede. Dit word algemeen aanvaar dat Teologie waarskynlik, benewens die Militêre Akademie, die mees "getransformeerde" fakulteit aan die Universiteit Stellenbosch is. Dit is boonop die fakulteit wat deesdae die predikante-opleiding van, benewens die NG Kerk, ook die Verenigende Gereformeerde Kerk en 'n paar ander kerke behartig. Hoewel ek 'n gelegitimeerde proponent van die NG Kerk is, is ek glad nie deel van die Fakulteit Teologie nie; ek is 'n personeellid van die Departement Filosofie aan die US.

4 Let wel daarop dat (soos Conradie met waardering erken) die hersiene uitgawe van GSS, anders as die oorspronklike uitgawe, 'n uitvoerige hoofstuk bevat (pp. 251-276) waarin ek in (hopelik) geen onsekere terme nie die ongeregtigheid in Suid-Afrika en die NG Kerk se verlede en hede erken en analiseer. 


\section{Ortodoksie versus ortopraksie}

Die implikasie van die geloofsbeskouing wat in GSS ontwikkel word, is dat ortopraksie (ooreenstemming ten opsigte van hoe ons behoort te lewe) as van groter waarde of belang beskou word as ortodoksie (ooreenstemming oor dogmas en formele belydenisaansprake). Let op die gekursiveerde woorde. Ek beweer nooit in GSS dat 'n strewe na ortodoksie totaal onbelangrik is of nooit nagejaag moet word nie. Al wat ek sê, is dat dit vir ons verstaan van 'n ter sake, eietydse geloof van minder belang is as die strewe na ortopraksie. Ek maak hierdie aanspraak om twee redes, een waarvan 'n empiriese begronding het, terwyl die tweede meer prinsipieel van aard is.

Die eerste, empiries geïnformeerde argument in hierdie verband is die doodgewoon histories observeerbare feit dat 'n universele akkoord oor dogma en belydenis nog nooit suksesvol was nie, en dat die kerk as gevolg daarvan deurentyd aan die skeur was of is. Dit is weliswaar so dat die Rooms Katolieke Kerk in die Weste 'n vorm van skynbare ortodoksie daarop nagehou het sedert die vroeë kerk tot en met die skeiding van die weë met die Oosters Ortodokse Kerk in die elfde eeu. Die "ortodoksie" van Rome was egter 'n wankelrige soort akkoord en is deur die eeue daarna voortdurend aangevreet deur beweerde "ketterye" wat "bestry" moes word. Hierdie "bestryding", soos dit veral in die Inkwisisie van die veertiende eeu en daarna beslag gekry het, verteenwoordig een van die donkerste episodes in die geskiedenis van die kerk. ${ }^{5}$

Daarna volg die Reformasie van die sestiende eeu wat sekerlik daarin geslaag het om onverantwoordbare dogmas en praktyke in die kerk van Rome aan die kaak te stel, en wat 'n deurslaggewende rol gespeel het in die oorgang na 'n moderne politieke bestel in Europa. Die Reformasie het egter in die naam van die (soms kompromielose) aandrang op ortodoksie die verskeurdheid van die kerk in die wêreld die norm gemaak. Dit is die groot beswaar van Desiderius Erasmus teen Luther en die Reformasie - nie dat hervorming bepleit word nie, maar dat die kerk geskeur word. (Sien

5 Die literatuur oor die inkwisisie, veral in Spanje, is onoorsigtelik. Let, vir 'n buitengewoon onthullende beeld van die motiewe en metodes van die inkwisisie, op die ontroerende fantasie van Ivan Karamazov oor die Groot Inkwisiteur se gesprek met die teruggekeerde Christus in die tronk. Vgl. Dostoevski 2002:246-264. 
hoofstuk 4, pp. 91-14 van GSS wat gewy word aan die myns insiens jammerlike verwaarlosing van Erasmus se teologie in ons tyd.)

Sedert die Reformasie prolifereer dogmas en kerke feitlik ongebreideld. Daarmee kom 'n kern-aspek van Christus se verstaan van die kerk volmondig in die gedrang: die oproep tot eenheid, wat vir die Christus van die Johannes-evangelie van soveel belang is dat Hy die geloofwaardigheid waarmee mense ("die wêreld") sal glo dat die Seun en die Vader een is, afhanklik stel van die eenheid van Sy volgelinge onder mekaar. "Ek bid dat hulle almal een mag wees, net soos U, Vader, in my is en ek in U, dat hulle ook in Ons mag wees sodat die wêreld kan glo dat U my gestuur het" (Johannes 17: 20-22, my klem).

Die tweede rede waarom ek ortopraksie belangriker ag as ortodoksie, is die feit dat geloof as die sorg om gesamentlike en gemeensame handeling ter wille en ten behoewe van die naaste, 'n veel groter impak op die wêreld het of kan hê as die akkoord van 'n leerstellige konsensus. In die geloof, soos ons dit veral werksaam sien in die sinoptiese evangelies, gaan dit telkens om iets ter wille of ten behoewe van ander mense te doen, en selde indien ooit om die soeke na ortodoksie. In sowel Jesus se Bergpreek as in sy gelykenisse wat die kern uitmaak van sy prediking, gaan dit om die betoning van barmhartigheid en die verduur van vervolging (Matt 5:7-12), om die radikalisering van die betekenis van die wet (egskeiding lê byvoorbeeld reeds daarin om bloot na 'n vrou te kyk om haar te begeer) (Matt 5:27-28), om die oproep om nie slegs die naaste nie, maar ook vyande lief te hê (Matt 5: 42-44), oor die onmoontlikheid om God en Mammon te dien (Matt 6:24), oor die insien van die ware bedoelinge van die wet (naamlik nie slegs as 'n akte van self-bevoordeling nie, maar die uitreik na en die sorg vir die een van wie ek die naaste geword het) (Luk 10:25-37). Uiteindelik gaan dit daaroor dat nie elkeen wat vir Hom "Here, Here" sê, die koninkryk van die hemele sal beërwe nie, slegs diegene "wat die wil doen van die Vader wat in die hemele is" (Matt 7:21). Daarin lê geloof. Die kerk - moeilik soos dit mag klink in ons tyd sowel as in ons herinnering aan die geskiedenis - glo vir soverre dit doen, nie vir soverre dit saamstem oor alles wat oor God beweer word nie. Die evangelie wek geloof wat die wêreld 'n beter plek maak sonder dat ons in staat hoef te wees om alles uit te pluis in terme van wat ons teoreties behoort te glo. 
Conradie verskil hier van my. Hy wys op die Belydenis van Belhar wat uiteraard ook 'n dokument is wat ek heelhartig onderskryf. Hierdie belydenis, skryf hy, laat “... vanuit die kerklike praktyk juis die klem ... val op die regte leer en [wys] daarom telkens dwaalleer [af]. Hier is 'n voorbeeld waar ortodoksie as fundamenteel belangrik geag is ter wille van ortopraksie" (Conradie 2015:148). Conradie is natuurlik reg in die sin dat die kerk nie sonder meer handel nie, maar dat dit in haar handelinge gestuur word deur een of ander geformuleerde ideaal. My probleem is nie soseer met laasgenoemde vanselfsprekende beginsel nie. My probleem lê veeleer by die aandrang daarop dat almal moet saamstem - d.i. ortodoksie bereik - alvorens die handeling wat die geloof is, volmondig aanbreek en volvoer (kan) word. Een van die ongelukkigste nalatenskappe van die Reformasie is presies die idee dat ons voortdurend konsensus moet soek oor'n proliferasie van kwessies - slawerny, apartheid, gay verhoudings - en dat hierdie obsessie met konsensus eenvoudig meebring dat "die wil van ons Vader wat in die hemel is" - nie gedoen word nie.

Belhar kan hier juis ook as 'n voorbeeld van my punt dien. Die Belydenis wat voortgevloei het uit die status confessionis van die tagtigerjare is 'n sieraad van Bybelinterpretasie ten aansien van sosiale onreg waaroor daar wêreldwyd (met die moontlike uitsondering van 'n aantal reaksionêre in die NG Kerk) saamgestem is. Dat die Belydenis nog nie amptelik deur die NG Kerk aanvaar is nie, is deesdae die gevolg van verspotte maatreëls in die NG Kerk se Kerkorde wat 'n wysiging van belydenis prakties onmoontlik makk, en het (as ons die NG kerkleiding mag glo) niks meer te make met die teologiese inhoud van die dokument nie. Ortodoksie kan oor die vreemdste goed gesoek word en hardnekkig wegbly. Soms is dit moeilik om die vraag te vermy: om watter werklike redes? Dit het baie jare geduur alvorens plaaslike kerke en later ook ringe en streeksinodes in die NG Kerkfamilie Belhar vir hulself aanvaar het en, veel belangriker, begin saamwerk het om beslag te gee aan die praksis wat 'n post-apartheid belydenisskrif tereg verwag, eerder as om voort te ploeter met 'n volgehoue, dog onwaardige en ongeloofwaardige proses om ortodoksie te soek.

Ek sê dus nie 'n soeke na ortodoksie is nooit geregverdig nie. Al wat ek probeer beklemtoon in GSS, is dat die soeke na ortopraksie belangriker is as die soeke na ortodoksie. Die geloof in die vorm van diens aan die naaste kan voortgaan en funksioneer sonder dat ons altyd in staat hoef te wees 
om met vers en kapittel te weet en te formuleer wat presies die dogma of geformuleerde belydenis is wat die geloof ondersteun. Die geloof moet in eerste en laaste instansie geleef word. Dit is gaaf as ons woord en daad rondom die geloof by mekaar kan uitbring. Dat ons selde daarin slaag, behoort die kerk nie te stuit in die uitleef van die liefde, en dus die praktyk van die geloof nie.

\section{Geloof sonder sekerhede?}

Conradie toon heelwat instemming met my aanspraak daarop dat geloof nie al te maklik met sekerheid verwar moet word nie. Hy skryf dat die "polemiese konteks" van my aanspraak "die gewaande sekerhede van 'n fundamentalistiese of evangeliese ortodoksie" is (2015:353). Hy wys tereg daarop dat, hoewel ek skepties is oor die identifikasie van geloof met sekerheid, ek wel in die onderskeid wat ek tref tussen wetenskaplike kennis en geloofskennis ruimte maak vir'n mate van sekerheid in die geloof. Weer: dit sou weinig sin maak om die radikale aanspraak te maak dat sekerheid nooit enige rol in die geloof speel nie. Daar is wel geen plek vir sekerheid in wetenskaplike kennis nie; laasgenoemde, so leer ons by Popper, is altyd niks meer nie as "valid, pending further evidence". Conradie wys tereg daarop dat hierdie soort sekerheid wat 'n rol speel in die geloofsbelewing, nie primêr in 'n epistemiese konteks verstaan moet word nie, maar eerder in die sin van die "convictions" (in onderskeiding van blote "beliefs") waarvan McClendon en Smith praat (in 'n boek wat ek in hierdie verband ter sprake bring en waarvoor Conradie groot waardering het. Vgl. McClendon \& Smith 1975). Conradie wys tereg daarop dat "Hoewel dit mag lyk na 'n weerspreking van sy eie [Van Niekerk se] argument, is daar vanuit hierdie standvastigheid wel ruimte vir geloofsekerheid of ten minste dan geloofsversekerdheid wat berus op versekering deur 'n ander" (Conradie 2015:354).

Hiermee stem ek saam. Ek meen dat'n korrekte verstaan van die Christelike geloof ruimte moet laat vir twyfel, of dan, 'n gebrek aan sekerheid wat dikwels ervaar word. Dit is nie bloot 'n empiriese waarneming nie. Geloofsonsekerheid (as ek die begrip mag gebruik) is onmiskenbaar deel van die geloofsbelewenis van Bybelse figure soos Job, Habakuk en de skrywers van talle Psalms. Belangriker nog: die Jesus wat ly en wat sterf aan 
die kruis skep nie by my die indruk van iemand wat oorloop van sekerhede nie. Hy bid in Getsemane dat die beker liewer by Hom sal verbygaan. Aan die kruis roep Hy vraend uit na die God wat Hom "verlaat" het. Op daardie vraag, kom geen duidelike of onmiddellike antwoord nie.

Ek sê nie daarmee dat sekerheid nie insgelyks ook 'n aanduibare plek in ander instansies van geloof het nie. Maar daardie sekerheid is nie in eerste instansie die sekerheid van epistemies begronde kennisaansprake wat vergelykbaar met dié van die wetenskap in die lewe van mense figureer nie. Dis eerder, soos ek in die boek probeer aantoon en Conradie tereg insien, die sekerheid wat voorspruit uit versekering; die sekerheid wat die vrug is van 'n verbintenis in 'n opregte en duursame verhouding. Dis dit gevolg daarvan om verseker te word/wees van iemand, eerder as van iets.

Hoewel Conradie oor laasgenoemde aspekte dit grootliks met my eens is, roep hierdie aansprake ander vrae by hom op - vrae oor "die publieke rol van godsdiens", asook die vraag of hier nie dalk gewerk word met 'n geloofsbeskouing wat godsdiens "triviaal" maak nie. Soos ek hom verstaan, vrees hy dat godsdiens, op die beoefening waarvan 'n mens wel 'n grondwetlike reg in Suid-Afrika en ander demokrasieë het, eintlik net geduld of getolereer word, en dat die klem op geloofsekerheid, met die gepaardgaande "godsdienstige identiteit" wat dit konstitueer, eintlik as "gevaarlik" beskou en hoogstens "geduld" word.

Hierop is my kort antwoord dat instansies van geloofsbelewenis wat gepaard gaan met die vlakke van "sekerheid" wat ons gesien het in die inkwisisie, die aksies van Engeland se "Bloody Mary" teen nie-Katolieke in die 1650's, die konflik in Noord-Ierland en die gebeure van 11 September 2001, bepaald iets is om te vrees, en sekerlik nie in enige demokratiese samelewing geduld behoort te word nie. Natuurlik het Conradie nie sulke ekstreme voorbeelde in gedagte as hy praat van sekerheid in die konstituering van 'n "godsdienstige identiteit" nie.

Laat ek daarom hieroor tweërlei sê: 1 . Persoonlik kan ek nie sien waarom die teenswoordige grondwetlike reëlings rondom godsdiensregte enige bedreiging inhou vir die ontwikkeling van 'n "godsdienstige identiteit", as 'n mens in laasgenoemde belang stel nie. 2. Ons leef in tye wat dramaties verskil van die tye toe godsdiens amper vanselfsprekend deel van mense se identiteit gevorm het, d.i. tye toe almal byvoorbeeld verplig was om kerk 
toe te gaan op Sondae. Ons het in die afgelope jare heeltemal te veel gesien dat religiositeit in baie kringe aanleiding gee tot vorme ekstremisme wat onverduurbaar is in enige samelewing.

Conradie se ander vraag is of die erkenning dat onsekerheid part en deel uitmaak van die geloof, die godsdiens nie "triviaal" maak nie. Ek weet nie of sy voorbeelde in hierdie verband al te gelukkig is nie. 'n Samelewing waarin godsdiens nie "triviaal" is nie, is, om 'n voorbeeld van Conradie te gebruik, een waarin mense vir kettery of morele oortredings op die brandstapel kon sterf. As die prys vir die "trivialisering" van die godsdiens egter is dat sulke praktyke nie meer moontlik is nie, dan kan ek nie anders nie as om sodanige "trivialisering" te verwelkom! Ek is volkome akkoord met die stelling van Berger en Zijderveld wat Conradie in hierdie bespreking aanhaal: "We can live with considerable uncertainty concerning our cognitive definitions of reality while at the same time being able to make moral judgements with great certainty" (Berger en Zijderveld, soos aangehaal deur Conradie 2015:352). Laasgenoemde bring ons terug by my punt in die vorige afdeling: Ons het nie volkome ortodoksie nodig om moreel reg te handel nie. Geloof self is om die lewe van die liefde te leef.

\section{Geloofkennis en wetenskaplike kennis}

Conradie bied op p. 354 'n helder en grootliks akkurate opsomming van die vernaamste posisies wat ek in GSS (en elders) ingeneem en verdedig het i.s. die verhouding tussen geloofskennis en wetenskaplike kennis. Hy is korrek dat ek in my beskouing wat aandring op die verskille tussen die twee soorte kennis sowel as die rol wat hierdie twee soorte kennis in mense se lewens speel, sterk beïnvloed is deur die denke van die latere Wittgenstein, d.i. die skrywer van die Philosophical Investigations, wat homself verklaar as die vernaamste kritikus van sy eie vroeëre Tractatus Logico Philosophicus. Die Wittgenstein van die Tractatus se sentrale aanspraak is dat die taal slegs een logiese vorm het, en dat alle kennis moet voortspruit uit die korrekte aanwending van daardie vorm. Dié aanspraak word volledig deur die latere Wittgenstein gerepudieer. Vir laasgenoemde het die taal, soos dit funksioneer is die veelheid van lewensvorme in die wêreld, 'n veelheid van logiese strukture, en lewer dit bygevolg ook'n veelheid van vorme van kennis op (Wittgenstein 1978). 
Conradie se spanning met my posisie begin reeds met sy gelade aanspraak dat my posisie neerkom op 'n "skeiding" tussen geloofs- en wetenskaplike kennis. Ek is nie seker of dit billik is om die onderskeiding wat ek tussen die twee soorte kennis tref, sonder meer te interpreteer as 'n skeiding nie, onafgesien van wat presies met laasgenoemde bewering bedoel sou kon word. Om hom aan te haal: "Ek gee toe dat die vermenging van wetenskap en geloof katastrofale gevolge inhou. Die gevare van boedelskeiding [!] is egter selfs nog groter" (Conradie 2015:355). Die vermeende "skeiding", as ek hom reg verstaan, is gevaarlik vir die Christelike teologie "gegewe langdurige dualistiese tendense. Die krag van die dualisme lê daarin dat die gevaar van reduksionisme raakgesien word. Aangesien interaksie onmoontlik is, word twee vlakke van kompleksiteit gehandhaaf sodat teenpole al twee beklemtoon word" (2015:356). Wat Conradie dus veral pla van my onderskeiding tussen die twee soorte kennis, is dat dit by implikasie verhoed dat die teologie sigself uitlaat oor aspekte van die een, ondeelbare eerlikheid. Hy skryf in sy slotsom: "Die geloofwaardigheid van teologiese uitsprake oor God is afhanklik van 'n verduideliking oor hoe God met die werklikheid verband hou ... die prys wat betaal word wanneer geloofskennis nie meer met wetenskaplike en ander vorms van kennis in verband gebring kan word nie is [weer eens] irrelevansie" (357).

Conradie se eie voorgestelde uitweg uit hierdie vermeende "dualistiese impasse" wat deur my beskouing geïmpliseer word, is 'n beroep op 'n soort kompleksiteitsdenke wat werk met die idee van "een multidimensionele werklikheid" (355). Conradie meen 'n mens moet praat van "verskillende vlakke van kompleksiteit waaraan'n bepaalde hiërargie van die wetenskappe korrespondeer (met al die gevare van so 'n hiërargie in ag genome). Die gevaar van reduksionisme is dan een waar twee vlakke van kompleksiteit met mekaar verwar en vervloei word sodat die een tot die ander gereduseer word" (355; my kursivering).

Ek vind Conradie se bespreking van hierdie derde "kreatiewe spanningsveld", en veral sy voorgestelde "oplossing" daarvan, besonder problematies. Hy dring in die eerste plek daarop aan dat "die werklikheid", hoewel dan kompleks, "een en multidimensioneel" moet wees. Dit behels 'n metafisiese veronderstelling wat geen begronding in Conradie se teks het nie. Daarby is hierdie "een, multidimensionele, komplekse" werklikheid hiërargies gestruktureer. Conradie wil werklik so 'n beskouing verdedig 
ongeag die "gevare" verbonde aan so 'n hiërargiese werklikheidsbeskouing (sien die gedeelte van die anhaling in die vorige paragraaf wat ek gekursiveer het). Is ons hier jou werklik terug by'n soort neoplatonisme met sy hiërargiese ryk van idees? Volgende vraag: waarom kan die Christelike teologie slegs sinvol oor God praat as daar syns-kontinuïteit tussen God en die skepping bestaan? Het ons hier met 'n nuwe weergawe van Aquinas se analogia entis-teorie of synsanalogie-teorie te make? ${ }^{6}$ Waarom kan slegs so 'n duidelik metafisiese teorie "geloofwaardigheid" aan die Christelike teologie se spreke oor God besorg?

My belangrikste punt van kritiek op hierdie bespreking van Conradie, is egter die feit dat, in sy besorgdheid oor die "relevansie" van die teologie, hy heeltemal te veel toegewings maak aan die sciëntisme, d.i. die standpunt wat aanvoer dat die enigste werklikheid wat daar is, dié een is wat deur die wetenskappe onthul word, en dat die enigste legitieme manier van praat oor die werklikheid, dié van die wetenskappe is. Juis daarom vind Conradie soveel heil in die begrip "kompleksiteit" aangesien dié begrip dit vir Conradie en geesgenote moontlik maak om daarop aan te dring dat "die natuurwetenskappe, die sosiale wetenskappe, filosofie, die kunste en teologie almal, betrekking het op een en dieselfde meervlakkige werklikheid" (Conradie 2014:356). Die implikasie is dat geloofskennis nie genoegsaam is of in isolasie van wetenskaplike kennis kan bestaan nie" (357).

Dit beteken egter, wat my betref, dat die teologie uiteindelik dit nie kan vermy om 'n naprater te word van die wetenskap - daardie "absoluut gesaghebbende gesagsbron van legitieme kennis" - nie. So 'n idee loop myns insiens die veel groter gevaar van die omarming van die sciëntisme. Na my mening het die wetenskap nie alleen geen monopolie op betroubare kennis nie (iets wat Conradie my wel in 'n stadium in sy artikel toegee) (354), maar is die wetenskap die een soort kennis wat juis en noodwendig altyd provisioneel geldig is, "pending further evidence", altyd uitgelewer aan nuwe benaderings, nuwe interpretasieraamwerke, nuwe feite. Verstaan my goed: ek geringskat nie die wetenskap nie. Die wetenskap is argumenteerbaar die mees indrukwekkende menslike prestasie van alle tye.

6 Vir 'n uitvoerige bespreking van Acquinas se analogia entis-teorie, wat onderskei moet word van sy logiese teorie oor die betekenis van God-taal (en inderwaarheid as voorveronderstelling van die logiese teorie dien) sien Van Niekerk 1983:79-107. 
Maar ons ganse menslike bestaan is nie afgestem op die soort kennis wat die wetenskap lewer nie. 'n Onderskeiding van Jürgen Habermas (1972:301350) kan ons hier help. Sy twee sentrale insigte aangaande die aard van kennis is dat kennis eerstens altyd 'n korrelaat is van belange (vandaar sy boek met die veelseggende titel Knowledge and human interests/Erkentniss und Interesse) en, tweedens, dat ons kennisverwerwing voortvloei uit die soort spesie wat ons is, en dus antropologies begrond is. Habermas onderskei dan tussen veral twee belange van waaruit kennis opgedoen word. Die eerste is die tegniese interesse, wat die belang is wat ons as 'n spesie daarby het om die reëlmatighede van ons natuurlike omgewing te verstaan ten einde daardie reëlmatighede/"wette" vir ons eie doeleindes aan te wend ten einde biologies te oorleef. Die empiries-analitiese wetenskappe is volgens Habermas die sistematiese vormgewing van hierdie soort kennisverwerwing.

Dis egter nie al soort kennis wat ons opdoen nie. Ons leef immers nie van brood alleen nie. Ons doen ook kennis op vanuit 'n tweede belang, naamlik die praktiese interesse. ${ }^{7}$ Dit is die interesse wat ons as 'n spesie het om, in dialoog met ander mense, tot 'n verstandhouding te probeer kom oor die soort lewe wat die moeite werd is en die waardes wat ons in ons menslike optrede moet probeer realiseer. Die histories-hermeneutiese wetenskappe (wat myns insien die teologie insluit) is dan die sistematiese vormgewing van hierdie interesse (Habermas 1972:301-350).

Die implikasie van Habermas se onderskeiding vir die gesprek tussen my en Conradie oor die derde "spanningsveld" wat lg. in GSS identifiseer, is m.i. dat die oënskynlike "dualisme" in my opvatting oor geloofs- en wetenskaplike kennis geen dualisme is wat aanleiding gee tot reduksionisme nie. Conradie is wat my betref die een wat veel meer op sy hoede moet wees vir reduksionisme met sy omarming van die idee van kompleksiteit. Habermas onderskei twee (eintlik drie; sien voetnoot 6) vorme van kennis omdat die belange van waaruit ons kennis opdoen, so radikaal van mekaar verskil. Die Christelike teologie, waarvan Conradie so 'n uitstekende eksponent is, hoef nie te vrees dat dit nie ter sake oor God praat as dit nie in staat is om die vermeende kontinuïteit tussen God en skepping deurentyd

7 Habermas ondersei ook 'n derde, naamlik die emansipatoriese interesse. Ek gaan, ter wille van ruimte, nie dit ook hier bespreek nie. 
raak te sien en te omskryf nie. Is dit nie immers die Prediker wat aanvoer dat "God is in die hemel en die mens is op die aarde" nie (Pred 5:1)?

Ons doen nie kennis op omdat ons 'n metafisiese gelyksoortigheid tussen God en alles in die werklikheid hoef te kan demonstreer nie. Anders gestel: betroubare kennis van die werklikheid spruit nie voort uit die ontologiese gelyksoortigheid van alles wat werklik is nie; dit spruit eerder voort uit die soort spesie wat ons is en die wyse waarop die kennis wat ons opdoen ons belange dien. Ons doen kennis op omdat ons lede is van 'n bepaalde spesie, 'n spesie met 'n verskeidenheid van behoeftes en belange, vir wie verskillende soorte kennis op verskillende maniere ondersteun en wat met verskillende soorte kennis op verskillende maniere oor die weg kom en hul weg in die wêreld vind.

Ek twyfel of hierdie response op die kwessies wat hy ophaal Conradie sal oortuig. Ek bedank hom egter opnuut vir die aandag wat hy aan my boek gewy het en die insigtelike kwessies wat hy aangeroer het. Ek glo hierdie is 'n gesprek wat ook verdere episodes sal oplewer.

\section{Bibliografie}

Bauman, Z 1993. Postmodern ethics. Oxford: Blackwell.

Berger, PI \& Zijderveld, A 2009. In praise of doubt: How to have convictions without becoming a fanatic. New York: HarperCollins.

Conradie, E 2015. Geloof sonder sekerhede? In gesprek met Anton van Niekerk. Stellenbosch Theological Journal, 1 (1), 345-359.

De Villiers, E 2018. Revisiting Max Weber's ethic of responsibility. Tübingen: Mohr Siebeck.

Dostoevsky, F 2002. The brothers Karamazov. New York: Farrar, Straus and Giroux.

Habermas, J 1972. Knowledge and human interests. London: Heinemann.

Jonas, H 1984. The imperative of responsibility. Chicago: University of Chicago Press. 
Levinas, E 1985. Ethics and infinity. Pittsburgh: Duquesne University Press.

McClendon, J Wm \& Smith, JM 1975. Understanding religious convictions. London: University of Nortre Dame Press.

Rossouw, HW 1993. Universiteit, wetenskap en kultuur. (Saamgestel en ingelei deur Anton van Niekerk) Kaapstad: Tafelberg.

Van Niekerk, AA 1983. Analogie en teologie: 'n krities-wysgerige ondersoek van die funksie van analogie-teorieë omtrent teologiese taalgebruik. Ongepubliseerde doktorale proefskrif. Stellenbosch: Universiteit Stellenbosch.

Van Niekerk, AA 2014. Geloof sonder sekerhede. Kaapstad: Lux Verbi.

Wittgenstein, L 1978. Philosophical investigations. (Tr. GEM Anscome) Oxford: Blackwell. 